\title{
Modified Capanna's Technique (Vascularized Free Fibula Combined with Allograft) as a Single-Stage Procedure in Post-traumatic Long-Segment Defects of the Lower End of the Femur: Outcome Analysis of a Series of 19 Patients with an Average Gap of $14 \mathrm{~cm}$
}

\author{
Dheenadhayalan Jayaramaraju ${ }^{1} \quad$ Hari Venkataramani ${ }^{2}$ Raja Bhaskara Rajasekaran ${ }^{1,}{ }^{\odot}$ Devendra Agraharam ${ }^{1}$ \\ Shanmuganathan Raja Sabapathy ${ }^{2}$ Shanmuganathan Rajasekaran ${ }^{1}$
}

\author{
${ }^{1}$ Department of Orthopaedics \& Trauma, Ganga Medical Centre and \\ Hospitals, Coimbatore, Tamil Nadu, India \\ ${ }^{2}$ Department of Plastic, Hand and Reconstructive Surgery, Ganga \\ Medical Centre \& Hospitals, Coimbatore, Tamil Nadu, India
}

Address for correspondence Raja Bhaskara Rajasekaran, MS, DNB, Department of Orthopaedics \& Trauma, Ganga Medical Centre \& Hospitals, 313, Mettupalayam Road, Coimbatore 641012, Tamil Nadu, India (e-mail: rajalibra299@gmail.com).

Indian J Plast Surg 2019;52:296-303

\begin{abstract}
Keywords

- Capanna technique

- allograft

- vascularized fibula

- distal femur bone defect

Objectives Salvage and reconstruction of posttraumatic defects of the long bone are complex due to the multiple procedures involved and increased chances of poor outcomes. We present the outcomes of the modified Capanna's technique-a reliable single-stage procedure of combining allograft and free vascularized fibular graft-in treating large posttraumatic bone defects in the distal third of the femur.

Study Design This is a retrospective analysis.

Materials and Methods Between April 2012 and September 2016, 19 patients with an average age of 33.8 years (range: 18-49 years) and an average defect of $14.5 \mathrm{~cm}$ (range: $9.5-20 \mathrm{~cm}$ ) in the distal femur were managed by the modified Capanna's technique. Bone union time and functional outcome using lower extremity functional score (LEFS) after union were noted.

Outcomes and Results Eighteen grafts went onto achieve bony union at an average of 6.6 months (range: 5-9), with an average knee flexion of 80 degrees (range: 45-110 degrees) and an average LEFS of 63 (range: 46-72). One patient had a nonunion with graft resorption at 8 months following persistent infection and was revised with debridement and augmenting the vascularized fibula from the other leg which went on to achieve union. Three patients had superficial infection, and three patients had delayed union.

Conclusion The modified Capanna's technique provided increased biology and enhanced structural stability and therefore is a good single-stage procedure in the reconstruction of posttraumatic long-segment defects of the distal femur.

Level of Evidence Level 4.

Level of Clinical Care Level I tertiary trauma center.
\end{abstract}

\section{Introduction}

The management of complex injuries of the distal femur associated with soft tissue damage and bone loss continues to be a major challenge for trauma surgeons. The problem

received

March 29, 2019

accepted after revision

September 11, 2019

published online

December 26, 2019 of reconstruction of these injuries is compounded by the chances of increased number of surgeries and high chances of nonunion. ${ }^{1,2}$ To reconstruct extensive bone defects of the distal femur, various techniques such as distraction osteogenesis, vascularized fibula grafts, Masquelet's induced
(C)2019 Association of Plastic

Surgeons of India

License terms

10.1055/s-0039-3400672 ISSN 0970-0358.

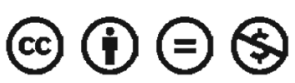


membrane technique, and allografts are commonly used..$^{3-5}$ Each technique has its own advantages, but uniformly they have the disadvantages of multiple surgeries and prolonged treatment. Working on the innovation by Capanna and his team, ${ }^{6}$ we proposed the Modified Capanna's techniquecombining a vascularized fibula with an allograft-to manage such injuries with bone defects of the distal femur. ${ }^{7}$ The modified Capanna's technique, a single-stage procedure, provides biology through the vascularized fibula and provides structural stability through an allograft and a locking plate to yield a successful outcome. Our modification of the original technique included creating a larger trough in the allograft to facilitate the easier sliding of the vascularized fibula and harvesting a skin island to monitor flap viability ( - Fig. 1). In this study, we present the midterm results of cases of posttraumatic distal femoral bone loss managed using the modified Capanna's technique.

\section{Materials and Methods}

Between April 2012 and September 2016, 19 patients with posttraumatic distal femoral bone loss underwent reconstruction using the modified Capanna's technique (combining an allograft with a vascularized free fibular graft). All the cases were a result of high-velocity trauma and were associated with open wounds. Nine cases presented to us initially, and the other 10 cases were referred to us after initial management elsewhere. Meticulous debridement by the plastic surgeons under loupe magnification was performed in all cases who primarily presented to us. Of the 19 cases, 8 (42.10\%) had intra-articular involvement. Articular reconstruction was performed in those eight cases during the initial surgery along with debridement (-Table 1). The patients in our study group had an average age of 33.8 years (range: $18-49$ years) with an average defect of $14.5 \mathrm{~cm}$ (range: $9.5-20 \mathrm{~cm}$ ) in the distal femur. The procedure involving a combined approach by an orthopaedic surgeon and a plastic surgeon was performed as primary reconstruction in 17 patients. In two patients, the reconstruction was performed following a failed primary internal fixation. Bony union and the functional outcome following union using LEFS (lower extremity functional score $)^{8}$ were calculated.

\section{Technique}

Our technique involved a plastic surgeon to assist in harvesting the vascularized free fibula and an orthopaedic surgeon

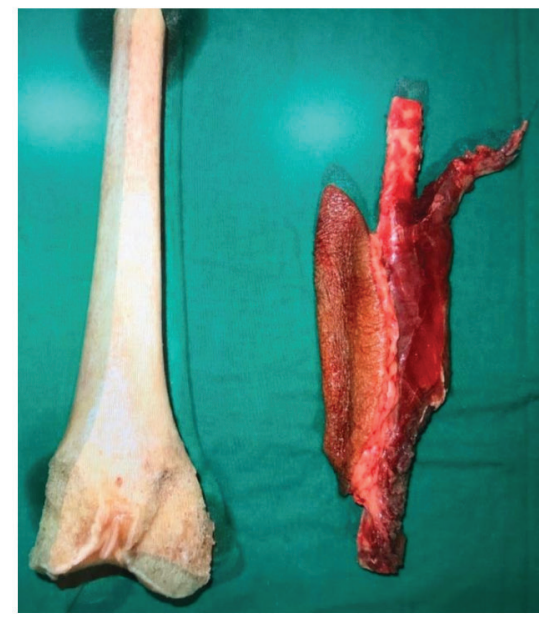

a

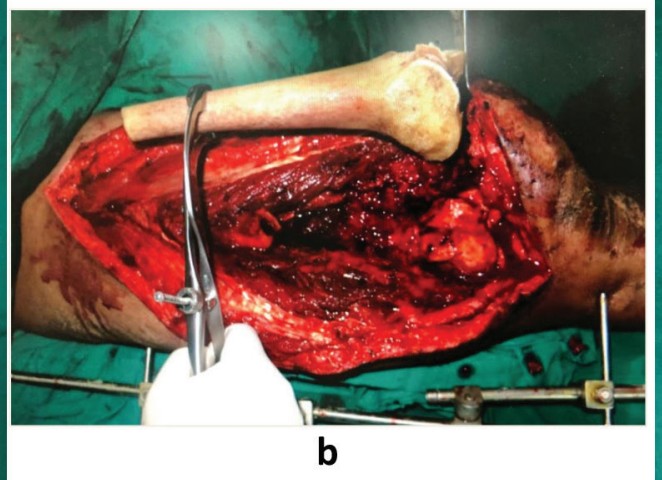

b

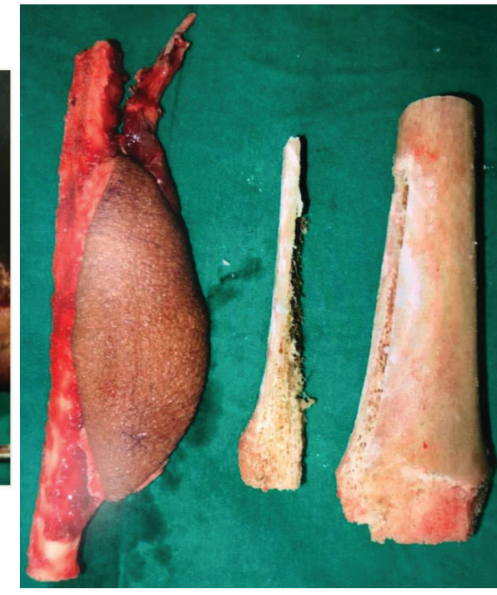

C
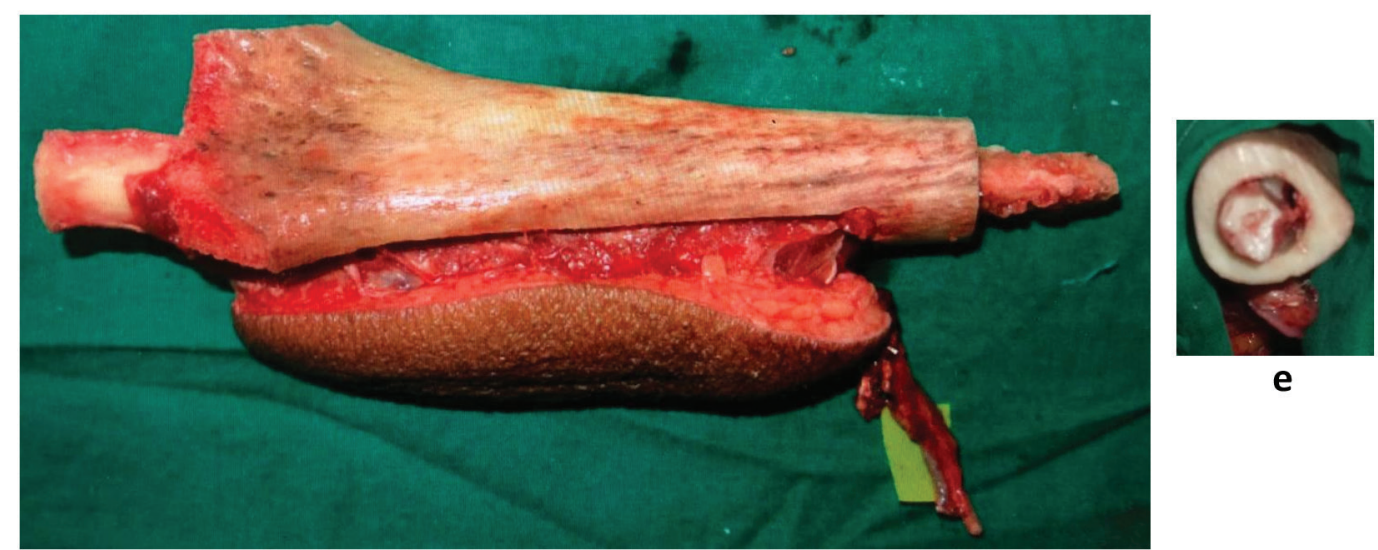

e

d

Fig. 1 Preparation of the allograft-vascularized fibula construct. (a) Allograft and vascularized fibula with the skin island. (b) Intraoperative measurement of required size of the allograft. (c) Sculpturing of the allograft to required size and creation of a trough for easier pegging of the pedicle. (d, e) Insertion of the fibula into the allograft. 
Table 1 Details of patients, results, and complications

\begin{tabular}{|c|c|c|c|c|c|c|c|c|c|}
\hline Patient & $\begin{array}{l}\text { Age } \\
\text { (in } \\
\text { years) }\end{array}$ & Sex & $\begin{array}{l}\text { Implants used } \\
\text { for articular } \\
\text { reconstruction } \\
\text { for intra- } \\
\text { articular } \\
\text { fractures }\end{array}$ & $\begin{array}{l}\text { Length } \\
\text { of the } \\
\text { defect (in } \\
\text { centimeters) }\end{array}$ & $\begin{array}{l}\text { Length of } \\
\text { allograft (in } \\
\text { centimeters) }\end{array}$ & $\begin{array}{l}\text { Union } \\
\text { Time (in } \\
\text { months) }\end{array}$ & $\begin{array}{l}\text { Knee } \\
\text { range of } \\
\text { motion (in } \\
\text { degrees) }\end{array}$ & LEFS & Complications \\
\hline 1 & 48 & Male & - & 16 & 16 & 5 & 90 & 57 & Superficial infection \\
\hline 2 & 20 & Male & - & 14 & 14 & 6 & 90 & 59 & $\begin{array}{l}\text { Partial skin island } \\
\text { necrosis }\end{array}$ \\
\hline 3 & 18 & Male & $\begin{array}{l}\text { Two cancellous } \\
\text { screws }\end{array}$ & 20 & 18 & 7 & 45 & 65 & $\begin{array}{l}\text { Partial skin island } \\
\text { necrosis with deep } \\
\text { infection }\end{array}$ \\
\hline 4 & 49 & Male & $\begin{array}{l}\text { One Herbert } \\
\text { screw and two } \\
\text { cancellous } \\
\text { screws }\end{array}$ & 10 & 10 & 6 & 60 & 46 & None \\
\hline 5 & 22 & Male & - & 13 & 14 & 6 & 80 & 66 & None \\
\hline 6 & 42 & Male & - & 12.5 & 12 & 5 & 90 & 67 & None \\
\hline 7 & 37 & Male & - & 11.5 & 12 & 7 & 70 & 59 & None \\
\hline 8 & 35 & Male & $\begin{array}{l}\text { One cancellous } \\
\text { screw }\end{array}$ & 9.5 & 10 & 8 & 60 & 52 & Delayed union \\
\hline 9 & 38 & Male & - & 16.5 & 17 & 7 & 45 & 59 & None \\
\hline 10 & 19 & Female & $\begin{array}{l}\text { One Herbert } \\
\text { screw }\end{array}$ & 17 & 16 & 6 & 100 & 70 & None \\
\hline 11 & 22 & Male & - & 16 & 17 & 8 & 95 & 68 & Delayed union \\
\hline 12 & 28 & Male & - & 17 & 17 & \begin{tabular}{|l} 
Infection \\
with \\
non-union \\
and graft \\
failure; \\
revised with \\
contralateral \\
vascularized \\
fibula: union \\
in 7 months \\
\end{tabular} & 60 & 58 & $\begin{array}{l}\text { Infection with } \\
\text { nonunion and graft } \\
\text { resorption }\end{array}$ \\
\hline 13 & 43 & Male & - & 14 & 14 & 8 & 85 & 67 & Delayed union \\
\hline 14 & 46 & Male & $\begin{array}{l}\text { One cancellous } \\
\text { screw }\end{array}$ & 13 & 13 & 7 & 80 & 71 & None \\
\hline 15 & 26 & Male & $\begin{array}{l}\text { One cancellous } \\
\text { screw }\end{array}$ & 16 & 16 & 6 & 90 & 70 & None \\
\hline 16 & 37 & Male & $\begin{array}{l}\text { One Herbert } \\
\text { screw and two } \\
\text { cancellous } \\
\text { screws }\end{array}$ & 15 & 15 & 9 & 105 & 67 & $\begin{array}{l}\text { Superficial infection } \\
\text { with delayed distal } \\
\text { union }\end{array}$ \\
\hline 17 & 39 & Male & - & 17 & 16.5 & 5 & 90 & 66 & None \\
\hline 18 & 19 & Male & - & 16.5 & 16 & 6 & 90 & 72 & None \\
\hline 19 & 25 & Male & $\begin{array}{l}\text { One Herbert } \\
\text { screw and one } \\
\text { cancellous screw }\end{array}$ & 14 & 13.5 & 7 & 110 & 59 & None \\
\hline
\end{tabular}

Abbreviation: LEFS, lower extremity functional score.

to sculpture the allograft to appropriate size and also to assist in osteosynthesis. A longitudinal incision on the medial side of the thigh extending up to the knee joint is the preferred incision of choice. ${ }^{9}$ Meticulous dissection between the sartorius and the vastus medialis muscle is performed to gain access to the femoral artery. The descending medial genicular artery and the accompanying veins of the femoral artery and its muscular branches are then identified. The level of the pedicle determines the decision to use the muscular or the descending genicular arteries for anastomosis.

The proximal and distal edges of the femur are debrided to achieve good bleeding edges. Preoperatively the length of 
the defect is measured on the radiograph, and an oversized allograft with a good medullary canal that would help in easily pegging in the vascularized fibula is chosen. The allograft is trimmed and sculptured in such a way that following fixation there is good contact between the host bone and the allograft. The free vascularized fibula harvested from the contralateral leg is at least $4 \mathrm{~cm}$ longer the defect, as the extra length would help to peg the fibula into the parent bone to increase bony contact ( $\boldsymbol{- \text { Fig. }} \mathbf{1}$ ). Keeping the orientation of the recipient vessels in mind, a slot is made on the medial side of the allograft. The construct is made by inserting the harvested fibula carefully into the upper end of the allograft. Care is taken to prevent damage to the vessels.

The fibula is then revascularized. In 16 patients, we used the muscular branches to the vastus medialis, and in the remaining 3 patients, we used the main descending genicular artery in the adductor canal. Veins were anastomosed with the corresponding venae comitantes. In 12 (63.1\%) cases, the saphenous vein, which was harvested below the knee from the same side of the fibula harvest, was used as a graft in anastomosis to extend the peroneal artery and vein to reach the recipient vessel. Following anastomosis, fixation was performed using a locking compression plate of adequate working length ( - Fig. 2). At least one screw was inserted to pass through the fibula to get a stable fixation of it. The skin island is incorporated along the suture line, and a gentle closure is performed.

Postperatively, an above-knee slab was used for 4 weeks followed by the initiation of knee mobilization. Full weight-bearing walking was begun after evidence of callus on both ends of the allograft with the native bone. Knee bending using CPM (continuous passive motion) was initiated following 1 month from surgery.

\section{Results}

Of the 19 patients, 18 went on to have a bony union. None of the 18 patients required any secondary procedure to achieve union. The average time to union was 6.6 months (range:
5-9 months), and the average knee flexion achieved was 80 degrees (range: 45-110 degrees). Two patients had superficial infection that resolved with intravenous antibiotics, and three patients had delayed union. Partial skin necrosis was seen in two patients following surgery, with one of them requiring skin grafting to achieve healing. The average functional outcome achieved as per LEFS was 63 (range: 46-72). Two illustrative cases have been presented ( - Figs. 3 and $\mathbf{4}$ ). The average follow-up period was 16.4 months (range: 7-27 months). All the results are tabulated and presented in - Table 1 .

One patient went have to have a nonunion following infection, with a failure of the graft to incorporate ( - Fig. 5). This patient was a 27 -year-old male with a $16-\mathrm{cm}$ bone gap of the distal femur following a road traffic accident. As part of damage control surgery, thorough debridement and primary skin closure were performed, and a joint spanning external fixator was applied. Clinical examination and blood investigations ruled out infection. Following the modified Capanna's technique, the

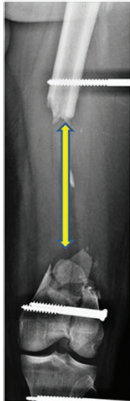

A

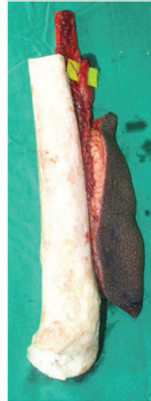

B

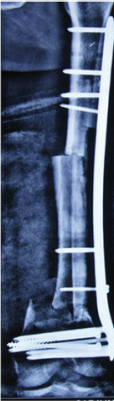

C

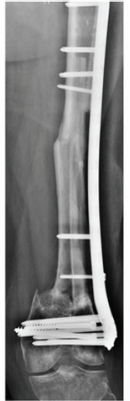

D

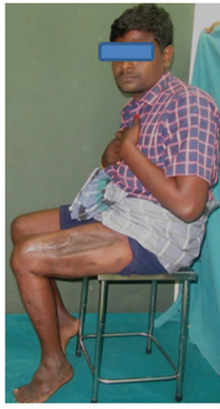

E
Fig. 3 (a) Illustrative case. A 22-year-old male with a 16-cm posttraumatic defect. (b) Prepared construct with the allograft and the vascularized fibula. (c) Postoperative X-ray after fixation. (d) Complete union achieved at 6 months, and (e) knee bending of 95 degrees achieved. (These images are provided courtesy of Rajasekaran RB, Jayaramaraju D, Venkataramani H, Agraharam D, Shanmuganathan RS, Shanmuganathan R. Successful reconstruction of a post-traumatic defect of $16 \mathrm{~cm}$ of the distal femur by modified Capanna's technique (vascularised free fibula combined with allograft)-A case report and technical note. Trauma Case Rep 2018; 17:29-32).

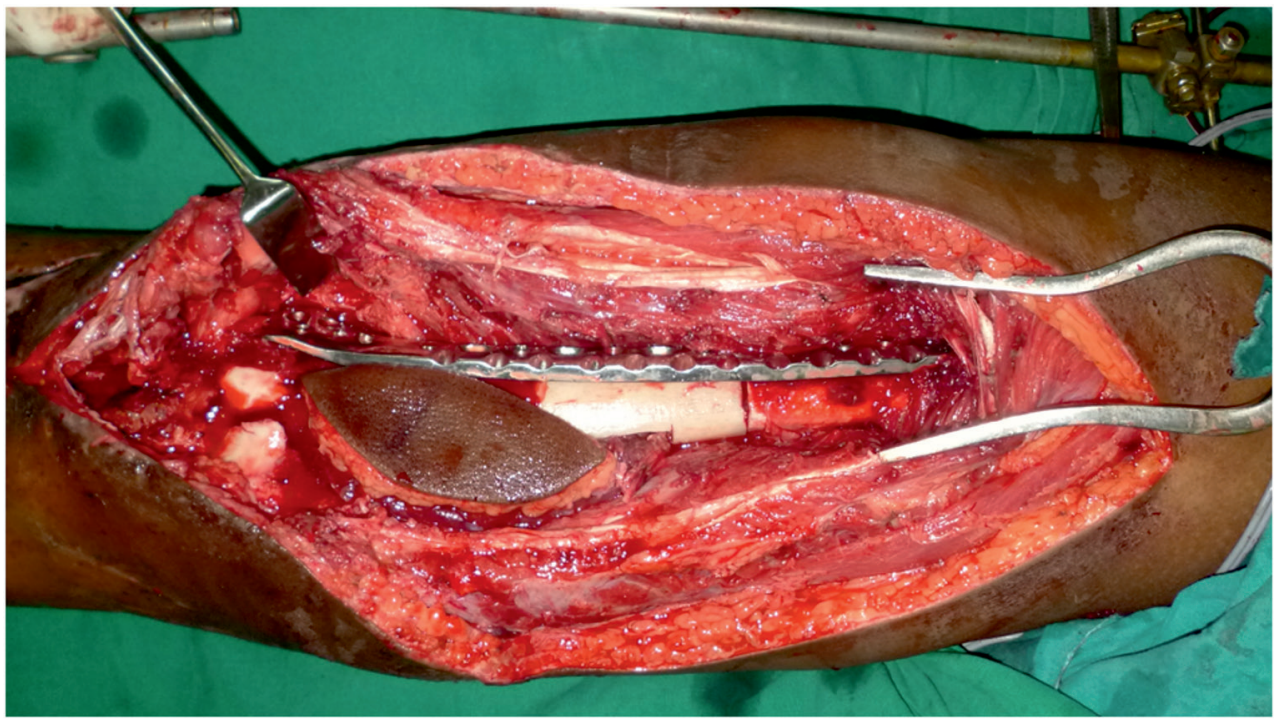

Fig. 2 Intraoperative image of the final inset before skin closure. 


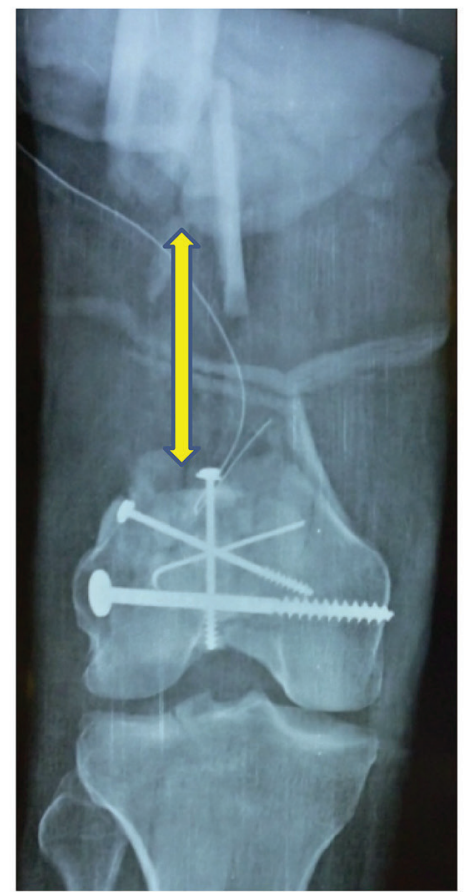

a

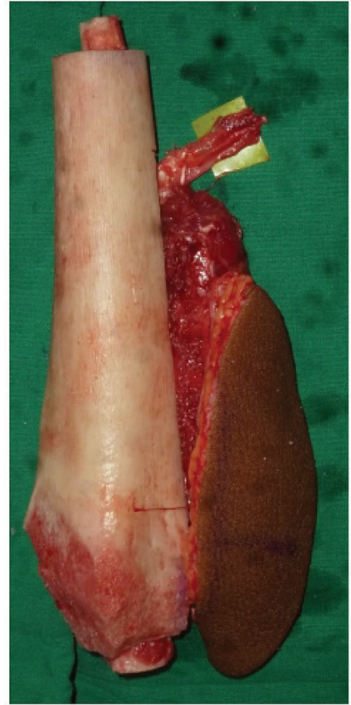

b

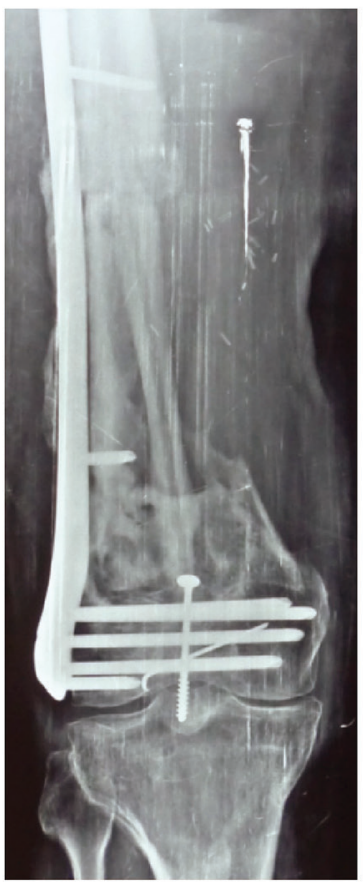

C

Fig. 4 Illustrative case. A 42-year-old male with a 12.5-cm defect (a) who was managed with the prepared construct to bridge the gap (b). Complete union at 7 months (c).

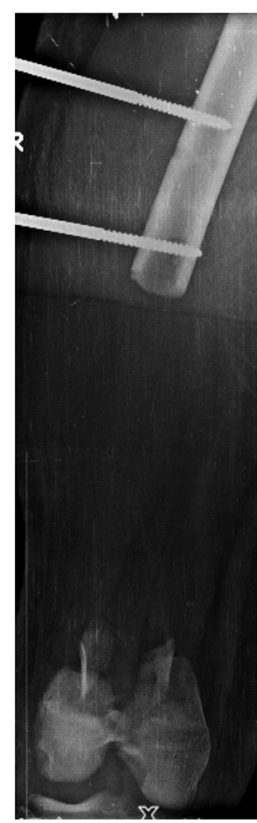

a

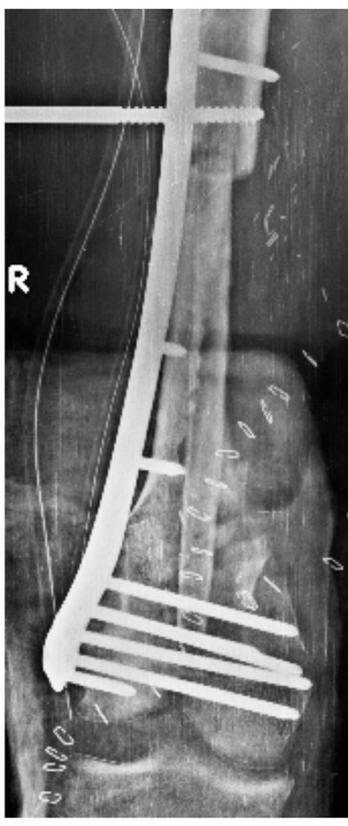

b

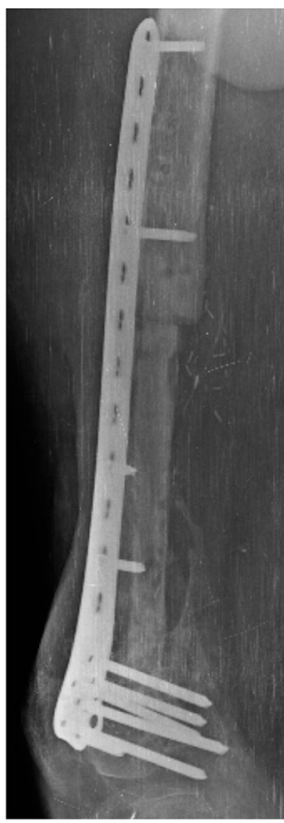

C

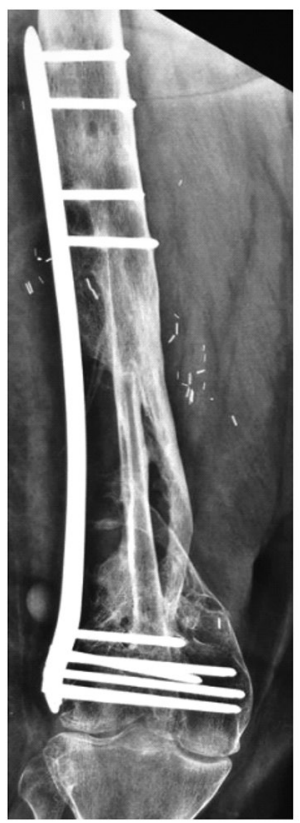

d

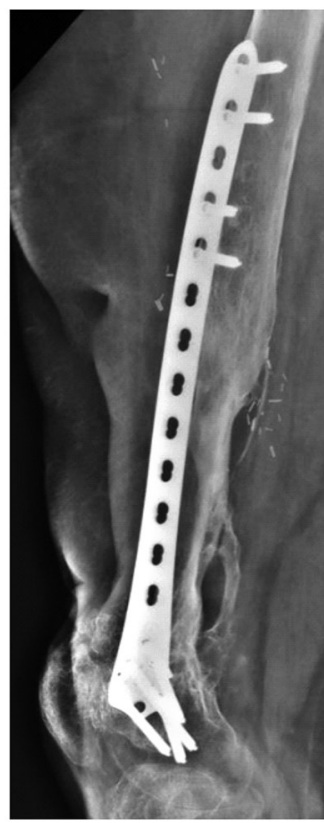

e

Fig. 5 Illustrative case. Following reconstruction of a $17-\mathrm{cm}$ defect (a, b), postoperatively the patient developed persistent infection that led to nonunion and resorption of the allograft $(\mathbf{c})$. Following debridement and anastomosis with the ipsilateral fibula, the patient went on to achieve a successful union at 6 months $(\mathbf{d}, \mathbf{e})$.

immediate postoperative period was uneventful. At the initial follow-up after 1 month, the patient presented with deep infection with a draining sinus. Debridement and antibiotic administration failed to resolve the issue. At 6 months follow-up, the patient presented to us with persistent discharge and the absence of any signs of bony union. On exploration, the fibula was completely necrotic and showed no signs of integration with the distal femur. However, the allograft shell was intact. A thorough debridement, removal of all necrotic bone tissue, and primary closure of the wound were performed. A locking plate 
was kept in situ. Subsequently, the wound healed and after 2 months, the patient was planned for another procedure. On exploring the wound, no evidence of infection was seen, and good fibrous tissue was seen around the defect. The vascularized fibula from the same leg was harvested and placed in the defect followed by anastomosis and autograft packing from the iliac crest. With regard to the anastomosis, during the first time, anastomosis of the descending genicular artery was performed. The second surgery involved a free transfer where a vein graft from the saphenous vein was used in the anastomosis of the descending branch of the lateral circumflex femoral artery and the venae comitantes. The patient had an uneventful postoperative period, and the graft showed union and incorporation with the parent bone at 6 months follow-up ( - Fig. 4d).

\section{Discussion}

In complex injuries of the lower limb, salvage is worthwhile if the final outcome is functionally better than the outcome achieved following an amputation and fitting the best prosthesis. Single-stage procedures with a high success rate will always be favorable if they are able to yield a good functional outcome. ${ }^{1,7,10}$ The treating surgeon must be aware of the length of the treatment and the financial cost involved, as they have a major implication on the family of the patient.

Managing large defects of the distal femur involving the articular surface are a challenge, and there are few options available. $^{1-3}$ Distraction osteogenesis is the treatment of choice in most centers around the world to manage such defects. However, distraction osteogenesis has a steep learning curve, and complications such as malalignment, malunion, and pin-tract infection are common. The treatment duration can be prolonged as the lengthening index varies between 1 and $1.14 \mathrm{~cm}$ per month.,7,10 Therefore, in defects of more than $10 \mathrm{~cm}$, the duration of distraction could be prolonged and emotionally demanding for the patient and the family. Moreover, it is technically demanding if the defect is very close to the knee joint, and spanning the joint may lead to increased chances of knee stiffness. Application of an external fixator or a ring in the level of the thigh can also be very cumbersome for the patient performing daily activities. ${ }^{11}$ In our institution, we use distraction osteogenesis with the Ilizarov method and the Limb Reconstruction System (LRS Pitkar, Pune, India) mainly for diaphyseal defects of the tibia, and we have achieved good outcomes in them.

The Masquelet technique for the management of long bone defects has been popularly used in managing traumatic defects of tibia as well as cases of infection. ${ }^{4,12}$ This technique has shown to achieve good results when used for diaphyseal defects of the tibia. There have been no reports with regard to the results of this technique while managing defects of the distal femur.

Vascularized bone grafts provide good bone with strong osteogenic capacity and high union potential. ${ }^{5}$ However, when a vacularized free fibula is used to reconstruct defects of the distal femur, it is associated with many problems. First of all, there is a major mismatch in the size difference between the large host bone and the slender donor bone. ${ }^{7}$ When the fibula is used for distal third defects of the femur, there is poor contact between the host bone and the donor bone, compromising the chances of union. Therefore, employing only a single fibula will not give adequate mechanical stability to the lower limb while reconstructing large defects. The fibular graft is not strong enough to allow early weight-bearing or walking, and there are high chances of fracture. To overcome this problem and to increase the strength of the graft, a double-barrel fibular graft has been proposed by a few authors., ${ }^{5,10}$ However, when a double-barrel graft is used, the length of the defect that can be reconstructed becomes significantly less, and reconstructing defects of more than $12 \mathrm{~cm}$ becomes a major challenge. When more than $20 \mathrm{~cm}$ of the fibula is harvested, problems can occur in the donor site also.?

The use of allografts in nonunions of the distal femur has been reported before. ${ }^{13}$ Using only allografts to reconstruct long-segment bone defects is associated with a high rate of complications. Apart from an increased rate of infection, Donati et $\mathrm{al}^{14}$ reported failure of the graft as a common reason for revision surgery and opined that allografts alone were not an ideal solution in managing long-segment defects. Laboratory studies of retrieved intercalary allografts have shown the maximum activity of osteogenesis to occur in the region where the allograft is in contact with the host. Insufficient contact with osteogenic tissue at the host-donor junction would result in higher chances of nonunion. Employing an allograft and vascularized fibular graft as a single construct overcomes all the problems discussed previously and helps in union by providing biology through the vascularized fibula and providing stability and increased contact through the allograft. We modified the original technique described by Capanna et $\mathrm{al}^{6}$ by creating a slot in the allograft for the insertion of the fibula by the inlay method and also harvesting a skin island with the pedicle for monitoring the viability of the vascularized fibula. The inlay technique is better than the onlay technique with regard to the promotion of vascularization and incorporation of the allograft. ${ }^{15,16}$ While the vascularized fibula provides extensive contact of osteogenic tissue to the allograft, the allograft provides mechanical strength and bone stock. Our modification of keeping a skin island to monitor flap viability was performed in all cases (-Figs. 1c, 2, and 3b). Any discoloration of the flap would indicate that there is a need to investigate the anastomosis and blood supply to the flap. Few authors have used imaging to study the biological behavior of the graft to good effect. In our practice, we found our technique very useful. Bone fixation was performed on the lateral side in all cases, and care must be taken to position the graft in the correct orientation so that kinking can be avoided during anastomosis.

Availability of allografts of massive size is another important aspect as it could dictate the timing of reconstruction. Ridha et $\mathrm{al}^{16}$ had to wait nearly 3 months for a patient in their series due to the nonavailability of a suitable allograft. In our entire series of 19 cases, we never had a problem procuring allografts mainly due to the presence of a bone bank in our institution. Being a tertiary-level trauma center, we harvested grafts from limbs that could not be salvaged and were amputated following 
high-velocity trauma. All the grafts were subjected to thorough processing and gamma irradiation prior to usage.

Modifications of the originally described Capanna technique have been described. ${ }^{17,18}$ Most of them have been for cases of bone tumors. Errani et al in their series of 81 bone tumors managed using allografts coupled with microvascular fibula used in intercalary reconstructions described it to be a useful procedure with a $94 \%$ limb survival rate. Though complications such as allograft fracture and infection were seen in 24 cases, a good-to-excellent functional outcome was seen in $91 \%$ of cases. ${ }^{17}$ Momeni et al described the "hemi-Capanna technique"-longitudinally splitting the allograft into half to allow more room for hypertrophy of the vascularized fibula-in reconstructing tibial defects of up to $13 \mathrm{~cm}$, with good success. ${ }^{18}$

With such an extensive procedure, complications are not uncommon. Extensive dissection and surgery on tissues following major trauma is associated with increased chances of infection. Four patients in our series had infection postoperatively. In two patients, the infection was superficial and settled with intravenous antibiotics. Debridement yielded a good result in one case with deep infection. One of our cases had persistent infection that did not resolve with antibiotics and debridement. Eventually, the infection resulted in nonunion and resorption of the allograft ( - Fig. 5c). Following a debridement and removal of all the necrotic bone, the patient underwent revision surgery with ipsilateral vascularized fibula and went to have a successful union with no infection thereafter. Hence, infection is the primary impediment in achieving a successful outcome in such cases.

The technique of reconstruction is complicated and requires meticulous planning and a combined team of both plastic and orthopaedic surgeons. The "orthoplastic" approach ${ }^{19,20,21}$ followed in our study is essential in this innovation. Our institution being a level 1 trauma center managing nearly 15,000 injuries annually gave us the experience to plan and execute these surgeries. With regard to vessel anastomosis and soft tissue coverage, experience plays a huge role in achieving a good outcome. All the 19 cases were managed by two experienced plastic surgeons with more than 20 years of experience and by two senior orthopaedic surgeons.

In our institution, the modified Capanna's technique has become the treatment of choice in managing large posttraumatic defects of the distal femur of more than $10 \mathrm{~cm}$. Our union results (94.7\%) following the surgery show that it stands as a good single-stage procedure in managing such injuries. This technique has shortened the treatment time (average: 6.6 months) compared with the long duration (average: 28 months) as shown in other studies. By not spanning the knee joint, as usually is the case in such injuries with distraction osteogenesis, we could achieve increased knee flexion (average: 80 degrees) by mobilizing the knees as early as 1 month from surgery and also achieve a good functional outcome (average LEFS of 63).

\section{Limitations of Our Study}

The major limitations of the study are its retrospective nature and the fact that it highlighted the results of only one center. The technique described by us requires a lot of technical expertise and may not be easily replicable. Moreover, our results were not compared with similar cases managed by other techniques or at other centers. Despite these limitations, our results show that our technique is a good single-stage procedure for managing such defects.

\section{Conclusion}

Our results show that by combining an allograft, which increases stability, and a vascularized fibula, which enhances biology, the modified Capanna's technique is a useful single-stage procedure yielding good functional outcomes in cases of posttraumatic long-segment bone defects of the distal femur. Enhancing chances of quicker union, early mobilization, and better outcomes, this technique is our preferred treatment of choice while managing such complex injuries.

\section{Note}

The study was performed in accordance with the ethical standards in the 1964 Declaration of Helsinki.

\section{Conflict of Interest}

The authors declare no conflict of interest.

\section{References}

1 Martinet O, Cordey J, Harder Y, Maier A, Bühler M, Barraud GE. The epidemiology of fractures of the distal femur. Injury 2000;31(Suppl 3):C62-C63

2 Hoffmann MF, Jones CB, Sietsema DL, Tornetta P, III, Koenig SJ. Clinical outcomes of locked plating of distal femoral fractures in a retrospective cohort. J Orthop Surg Res 2013;8:43

3 Saridis A, Panagiotopoulos E, Tyllianakis M, Matzaroglou C, Vandoros N, Lambiris E. The use of the Ilizarov method as a salvage procedure in infected nonunion of the distal femur with bone loss. J Bone Joint Surg Br 2006;88(2):232-237

4 Wang X, Luo F, Huang K, Xie Z. Induced membrane technique for the treatment of bone defects due to post-traumatic osteomyelitis. Bone Joint Res 2016;5(3):101-105

5 Bumbasirevic M, Stevanovic M, Bumbasirevic V, Lesic A, Atkinson HDE. Free vascularised fibular grafts in orthopaedics. Int Orthop 2014;38(6):1277-1282

6 Capanna R, Bufalini C, Campanacci C. A new technique for reconstructions of large metadiaphyseal bone defects: a combined graft (allograft shell plus vascularized fibula). Orthop Traumatol 1993;2:159-177

7 Venkatramani H, Sabapathy SR, Dheenadayalan J, Devendra A, Rajasekaran S. Reconstruction of post-traumatic long segment bone defects of the lower end of the femur by free vascularized fibula combined with allograft (modified Capanna's technique) Eur J Trauma Emerg Surg 2015;41(1):17-24

8 Binkley JM, Stratford PW, Lott SA, Riddle DL; North American Orthopaedic Rehabilitation Research Network. The Lower Extremity Functional Scale (LEFS): scale development, measurement properties, and clinical application. Phys Ther 1999;79(4):371-383

9 Venkatramani H, Sabapathy SR, Nayak S. Free-flap cover of complex defects around the knee using the descending genicular artery as the recipient pedicle. J Plast Reconstr Aesthet Surg 2014;67(1):93-98

10 Lasanianos NG, Kanakaris NK, Giannoudis PV. Current management of long bone large segmental defects. Orthop Trauma 2009;24(2):149-163 
11 Vargas Barreto B, Caton J, Merabet Z, Panisset JC, Pracros JP. Complications of Ilizarov leg lengthening: a comparative study between patients with leg length discrepancy and short stature. Int Orthop 2007;31(5):587-591

12 Krappinger D, Lindtner RA, Zegg M, Dal Pont A, Huber B. Masquelet technique for the treatment of large dia- and metaphyseal bone defects [in German]. Oper Orthop Traumatol 2015;27(4):357-368

13 Kanakeshwar RB, Jayaramaraju D, Agraharam D, Rajasekaran S. Management of resistant distal femur non-unions with allograft strut and autografts combined with osteosynthesis in a series of 22 patients. Injury 2017;48(Suppl 2):S14-S17

14 Donati D, Di Bella C, Colangeli M, Bianchi G, Mercuri M. The use of massive bone allografts in bone tumour surgery of the limb. Curr Orthop 2005;19:393-399

15 Chang DW, Weber KL. Use of a vascularized fibula bone flap and intercalary allograft for diaphyseal reconstruction after resection of primary extremity bone sarcomas. Plast Reconstr Surg 2005;116(7):1918-1925

16 Ridha H, Bernard J, Gateley D, Vesely MJ. Reconstruction of large traumatic segmental defects of the femur using segmental allograft with vascularized fibula inlay. J Reconstr Microsurg 2011;27(6):383-390

17 Errani C, Ceruso M, Donati DM, Manfrini M. Microsurgical reconstruction with vascularized fibula and massive bone allograft for bone tumors. Eur J Orthop Surg Traumatol 2019;29(2):307-311

18 Momeni A, Weber KL, Kovach SJ. A modification of an established method of intercalary extremity bone defect reconstruction: the "hemi-Capanna" technique. Ann Plast Surg 2018;81(2):240-243

19 Bakri K, Stans AA, Mardini S, Moran SL. Combined massive allograft and intramedullary vascularized fibula transfer: the Capanna technique for lower-limb reconstruction. Semin Plast Surg 2008;22(3):234-241

20 Jordan DJ, Malahias M, Khan W, Hindocha S. The ortho-plastic approach to soft tissue management in trauma. Open Orthop J 2014;8:399-408

21 Boriani F, Ul Haq A, Baldini T, et al. Orthoplastic surgical collaboration is required to optimise the treatment of severe limb injuries: A multi-centre, prospective cohort study. J Plast Reconstr Aesthet Surg 2017;70(6):715-722 